\title{
An Effectiveness Evaluation of a Primary Care-Embedded Clinical Pharmacist-Led Intervention Among Blacks with Diabetes
}

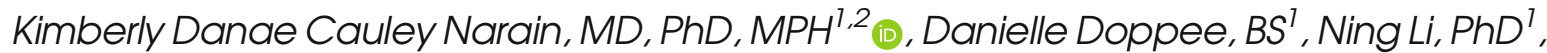 \\ Gerardo Moreno, MD, MSHS ${ }^{3}$, Douglas S. Bell, MD, PhD ${ }^{1,5}$, Amanda L. Do, MPH ${ }^{5}$, \\ Robert W. Follett, B.S. ${ }^{5}$, and Carol M. Mangione, MD, MSPH ${ }^{1,4}$
}

\begin{abstract}
'Department of Medicine, Division of General Internal Medicine and Health Services Research (GIM/HSR), University of California, Los Angeles, Los Angeles, CA, USA; ${ }^{2}$ Center for Health Advancement, Fielding School of Public Health, University of California, Los Angeles, Los Angeles, CA, USA; ${ }^{3}$ Department of Family Medicine, David Geffen School of Medicine, UCLA, Los Angeles, CA, USA; ${ }^{4}$ Health Policy and Management, Fielding School of Public Health, UCLA, Los Angeles, CA, USA; ${ }^{5}$ Clinical and Translational Science Institute, University of California, Los Angeles, Los Angeles, CA, USA.
\end{abstract}

BACKGROUND: Black individuals with type 2 diabetes suffer disproportionate morbidity and mortality relative to whites with type 2 diabetes, irrespective of health insurance coverage.

OBJECTIVE: Examine the impact of a primary careembedded clinical pharmacist-led intervention (UCMyRx) on cardiovascular risk factor control among blacks with type 2 diabetes in a large healthcare system. DESIGN: We used data extracted from the electronic health records (EHR) system and a difference-indifferences study design with a propensity-matched comparison group to evaluate the impact of UCMyRx on HbAlc and systolic blood pressure (SBP) among black patients with type 2 diabetes, relative to usual care.

PARTICIPANTS: Individuals with type 2 diabetes identified as either black or African American in the EHR that were $\geq$ 18 years of age that had the following observations during the study window $(03 / 02 / 2013-12 / 31 / 18$ : (1) HbAlC $\geq$ $8 \%$, at least once, anywhere between 365 days before and 14 days after the UCMyRx visit and a follow-up HbAlc measure within 120 to 365 days after the visit and/or (2) SBP $\geq 140 \mathrm{mmHg}$ at least once between 365 days before and 14 days after the UCMyRx visit that had a follow-up SBP measure within 120 to 450 days after the visit.

INTERVENTION: UCMyRx pharmacists review labs and vital signs, perform medication reconciliation, use a standardized survey to assess barriers to medication adherence, and develop tailored interventions to improve medication adherence.

MAIN MEASURES: Change in HbAlc and change in SBP from before to after the first UCMyRx visit.

KEY RESULTS: Having at least one visit with a UCMyRx clinical pharmacist was associated with a significant reduction in HbAlc $(-0.4 \%, p$ value $=.01)$; however, there was no significant impact on SBP $(-.051 \mathrm{mmHg}, p$ value $=0.74)$.

CONCLUSIONS: The UCMyRx intervention is a useful strategy for improving HbAlc control among blacks with type 2 diabetes.

Received October 31, 2019

Revised February 7, 2020

Accepted February 14, 2020

Published online March 6, 2020
KEY WORDS: diabetes; "racial disparities"; pharmacist; "medication adherence"; "quality of care"; intervention.

J Gen Intern Med 35(9):2569-75

DOI: $10.1007 / \mathrm{s} 11606-020-05750-0$

(c) Society of General Internal Medicine 2020

\section{INTRODUCTION}

Type 2 diabetes is an enormous public health problem. In 2017 expenditures associated with diabetes topped 237 billion dollars in direct and 90 billion in indirect costs, respectively. ${ }^{1}$ Type 2 diabetes disproportionately affects the black population. In particular, blacks have a higher prevalence of diabetes $(13.2 \%$ vs. $7.6 \%)$ and have anywhere from a 50 to $100 \%$ greater disease burden from complications such as kidney disease, lower extremity amputations, retinopathy, and cardiovascular disease, relative to non-Hispanic whites. ${ }^{2,3}$

A large portion of racial morbidity difference from diabetes can be explained by differences in cardiovascular risk factor control across racial groups. ${ }^{4}$ Studies have found that even among insured patients with diabetes, relative to non-Hispanic whites, blacks with diabetes are less likely to have HbA1c, LDL, and blood pressure levels that are consistent with guidelines. ${ }^{5,6}$ Differences in the quality of care received across racial groups are a key driver of the racial disparities in cardiovascular risk factor control. Studies indicate that even after controlling for access to care, racial/ethnic minorities are less likely than non-Hispanic whites to have annual HbAlc and cholesterol testing. ${ }^{7}$

Another important factor underlying disparities in risk factor control is medication adherence. Studies have found that among patients with diabetes, blacks are more likely to report not taking medications in accordance with their doctor's instructions and are more likely to discontinue diabetes medications, relative to nonHispanic whites. ${ }^{8,9}$ The drivers of non-adherence among blacks with diabetes are multifactorial and include reduced health literacy, medication misbeliefs, concerns about medication side effects, and medication costs issues. ${ }^{10-13}$ 
Results from a few small randomized clinical trials suggest that primary care-based pharmacist-led management, a delivery system design intervention that uses clinical pharmacists to address care quality and patient self-management behavior, may be an effective strategy for improving cardiovascular risk factor control among black individuals with diabetes. Rothman et al. found that minorities with Hbalc $\geq 8$, randomized to an intervention in which a clinical pharmacist provided patient education, addressed barriers to care, and managed cardiovascular risk factors using algorithms, during monthly visits, had reductions in $\mathrm{HbAlc}$ and systolic blood pressure (SBP) of $0.8 \%$ and $9 \mathrm{mmHg}$, respectively, after 12 months. ${ }^{14}$ Jaber et al. found that after 4 months, black individuals with diabetes, randomized to an intervention in which a clinical pharmacist provided diabetes education, lifestyle modification counseling, as well as instruction in home glucose monitoring and hypoglycemic regimen adjustment, had statistically significant reductions in $\mathrm{HbAlc}$ levels, compared with individuals randomized to usual care. ${ }^{15}$

While small RCTs have shown efficacy of primary carebased pharmacist-led management interventions for improving cardiovascular risk factor control among black individuals with diabetes, no effectiveness studies of this intervention in this population have been done. Individuals participating in RCTs are often more motivated and less sick than the general population. Adherence to intervention protocol is typically much stricter in RCTs than it is in every day practice. ${ }^{16}$ Consequently, the performance of primary care-embedded pharmacist-led management interventions among black individuals with type 2 diabetes, in a real-world context, remains uncertain. The objective of this study is to evaluate the effectiveness of a primary care-embedded clinical pharmacist-led management intervention, implemented in a large healthcare system, on cardiovascular risk factor control, among black patients with type 2 diabetes.

\section{METHODS}

\section{Setting}

The University of California Los Angeles (UCLA) is an academic medical center comprised of four hospitals and more than 180 medical practices throughout Southern California.

\section{Data Extraction}

The electronic health records (EHR) system was implemented at UCLA in March 2013. We obtained EHR data for all patients in the exposure and usual care groups. The abstracted data included medical encounter types, demographics, diagnoses, vital signs, laboratory test results, prescription medications, and health insurance coverage variables.

\section{Exposure: UCMyRx Visit}

In January 2012, UCLA began the UCMyRx initiative. As of October 2018, the program existed in 32 clinics. UCMyRx involves embedding clinical pharmacists trained in motivational interviewing into primary care practices to co-manage complex patients along with their primary care physicians. Individuals can access the UCMyRx program in a number of ways including by physician, clinical care coordinator, or selfreferral. Additionally, individuals in the UCLA Diabetes Registry, meeting one or more of the following criteria: (1) a $\mathrm{HbA} 1 \mathrm{C} \geq 9 \%$, (2) a $\mathrm{SBP} \geq 140 \mathrm{mmHg}$, (3) an $\mathrm{LDL} \geq$ $130 \mathrm{mg} / \mathrm{dL}$, and (4) on $\geq 5$ prescription medications, are contacted to schedule a consultation with a UCMyRx pharmacist. In the initial UCMyRx visit, clinical pharmacists review vital signs and labs, order labs as needed, perform medication reconciliation, assess medication adherence using a standardized survey and, based on the results of the survey, implement an intervention to improve medication adherence (Table 1). For example, survey responses that indicate out-of-pocket costs as a barrier to adherence would prompt the pharmacist to look for less expensive therapeutic options, patientassistance programs, and generic substitutions. The pharmacist schedules follow-up visits with the patient and supplements the visits with e-mails and phone calls as needed. The results of all assessments and recommendations regarding medication changes are communicated to the primary care physician through the EHR.

The exposure group included adults with any instance of ICD-9/10 diagnosis code for type 2 diabetes, race either black or African American, and $\geq 18$ years of age that had at least one face-to-face visit with a UCMyRx clinical pharmacist, during the study window (03/02/2013-12/31/2018). The exposure population for the $\mathrm{HbAlc}$ analyses was limited to adults that had $\mathrm{HbA} 1 \mathrm{C} \geq 8 \%$, at least once, anywhere between 365 days before and 14 days after the visit and a follow-up $\mathrm{HbA} 1 \mathrm{c}$ measure within 120 to 365 days of the visit. The SBP population was limited to adults that had $\mathrm{SBP} \geq 140 \mathrm{mmHg}$ at least once, between 365 days before and 14 days after the UCMyRx visit that had a follow-up SBP measure within 120 to 450 days after the visit. The index date for the exposure population was the date of the first UCMyRx visit.

Table 1 Promoting Adherence Through Tailored Interventions

\begin{tabular}{ll}
\hline \hline Barrier & Intervention \\
\hline Out-of-pocket costs & $\begin{array}{l}\text { Therapeutic substitutions, drug assistance } \\
\text { programs, \$4 generics, mail order } \\
\text { prescriptions }\end{array}$ \\
$\begin{array}{l}\text { Mail order, advise 3-month refills } \\
\text { cost) }\end{array}$ & $\begin{array}{l}\text { Simplify regimen (change to daily long } \\
\text { acting, delete unnecessary/dangerous } \\
\text { megimen complexity }\end{array}$ \\
$\begin{array}{l}\text { medils) suggest change to combination } \\
\text { Beliefs about } \\
\text { medications/condition }\end{array}$ & $\begin{array}{l}\text { Education, motivational interviewing, } \\
\text { medication action plan }\end{array}$ \\
Organizational difficulties & Pill boxes, other behavioral strategies \\
\hline
\end{tabular}




\section{Usual Care}

The usual care group came from UCLA patients, with any instance of ICD-9/10 diagnosis code for type 2 diabetes, identified in the EHR as black or African American that were $\geq 18$ years of age that had at least 2 visits to one or more UCLA primary care clinics, $\geq 2$ years apart, during the study window. The population used for the HbAlc analyses was further limited to the population that had $\mathrm{HbA1C} \geq 8 \%$, at least once, anywhere between 365 days before and 14 days after a randomly generated index date, between the two primary care visits and a follow-up HbA1c measure within 120 to 365 days of the index date. The SBP population was limited to adults that had SBP $\geq 140 \mathrm{mmHg}$ at least once, between 365 days before and 14 days after the randomly generated index date that had a follow-up SBP measure within 120 to 450 days after the index date. Usual care patients came from clinics both with and without UCMyRx pharmacists; however, they did not have a visit with a UCMyRx pharmacist.

\section{Propensity Score Matching Analysis}

Since it is not possible to randomize patients to the UCMyRx program, we use propensity score matching to create comparable cohorts of UCMyRx and usual care patients. ${ }^{17}$ Logistic regression models were used to generate propensity scores. Variable choices for the propensity scores were informed by the extant literature and included pre-index ( $\mathrm{HbAlc}$ and SBP levels, age, gender, Charlson Comorbidity Index (CCI), Diabetes Severity Index (DSI) ${ }^{18}$, serious mental illness (bipolar disorder, schizophrenia, major depression), having seen an endocrinologist (yes/no), number of diabetes medications, total number of prescription medications, and health insurance status (private, Medicare, Medicaid, Medicaid + Medicare)). ${ }^{6}$,

13, 19 Variables for insulin use, language, neighborhood-level educational status, body mass index, and smoking status were initially included in the propensity score models but they were removed due to the lack of a statistically significant association with treatment status. Each UCMyRx patient was matched to one comparable usual care patient using the nearest neighbor matching method. ${ }^{20}$ Separate propensity score matching was done for each outcome. Post-matching there were no statistically significant differences between the UCMyRx and usual care groups (Table 2).

\section{Outcomes}

Our primary outcomes were pre- to post-index changes in $\mathrm{HbAlc}$ and SBP levels. The pre-index HbAlc was the closest value to the index date with a window of 365 days before the index date and 14 days after. The pre-index SBP was the mean of the 3 values closest to the index date with a 365-day window before and a 14-day window after. The post-index $\mathrm{HbA1c}$ was the closest value to 180 days after the index date with a window of 120 to 365 days after the index date. The post-index SBP was the mean of the 3 values closest to
365 days after the index date with a 120 - to 450 -day window after the index date. ${ }^{19}$

\section{Statistical Analysis}

$\mathrm{R}$ statistical software was used for all analyses. The unit of analysis was the patient. We calculate descriptive statistics for all variables in the models, across treatment status, using the $t$ test and chi-squared test for continuous and dichotomous/ categorical variables, respectively. To evaluate the effect of the UCMyRx program on HbA1c and SBP, we performed difference-in-differences (DID) analyses. The DID study design is well-suited to assess the effects of the UCMyRx intervention given that it is able to remove the influence of other interventions such as a system-wide diabetes care quality improvement initiative, provided both the UCMyRx and usual care groups are exposed to the intervention and both groups are affected by the intervention in the same way. The use of propensity score matching helps ensure that the UCMyRx and usual care groups are balanced on observable factors that may influence how they would respond to a given intervention. ${ }^{21}$ We used linear mixed effects models that include an indicator for time (post-index vs. pre-index) that was coded as " 1 " if the observation was from the post-index period and coded "0" otherwise, an indicator for group (UCMyRx vs. usual care) that was coded as " 1 " if the observation was from the UCMyRx group and coded as " 0 " otherwise and the interaction between time and group, among our matched samples. ${ }^{22}$ Specifically, the between-group differences in the change of the outcome variables, post-index, were estimated by the interaction effects. The models also included random effects to take into account data clustering within each pair of matched UCMyRx and usual care patients and data clustering within each patient. The "patient" random effects were nested within the "cluster" random effects.

\section{Sensitivity Analyses}

To assess if UCMyRx effects were stronger among individuals with worse cardiovascular risk factor control, we conducted analyses in which we limited our HbA1c and SBP samples to individuals that had $\mathrm{HbAlc} \geq 9 \%$ and $\mathrm{SBP} \geq 150 \mathrm{mmHg}$, at least once during the pre-index period, respectively. To assess if UCMyRx effect differences observed across populations with more or less controlled risk factors were statistically significant, we repeated analyses with the entire matched sample and included a risk indicator coded as " 1 " if the patient had worse risk factor control and coded " 0 " otherwise. A statistically significant interaction between the time, group, and risk indicators would indicate statistically significant differences in UCMyRx effects, across patient populations, with more or less controlled risk factors. To assess the impact of UCMyRx across patients with different levels of comorbidity, we ran analyses stratified by Charlson Comorbidity Index (CCI) tercile. To assess for a dose-response effect of UCMyRx, we ran analyses comparing individuals with face- 
Table 2 Descriptive Statistics by Treatment Status for the HbA1c Sample (Unmatched and Matched)

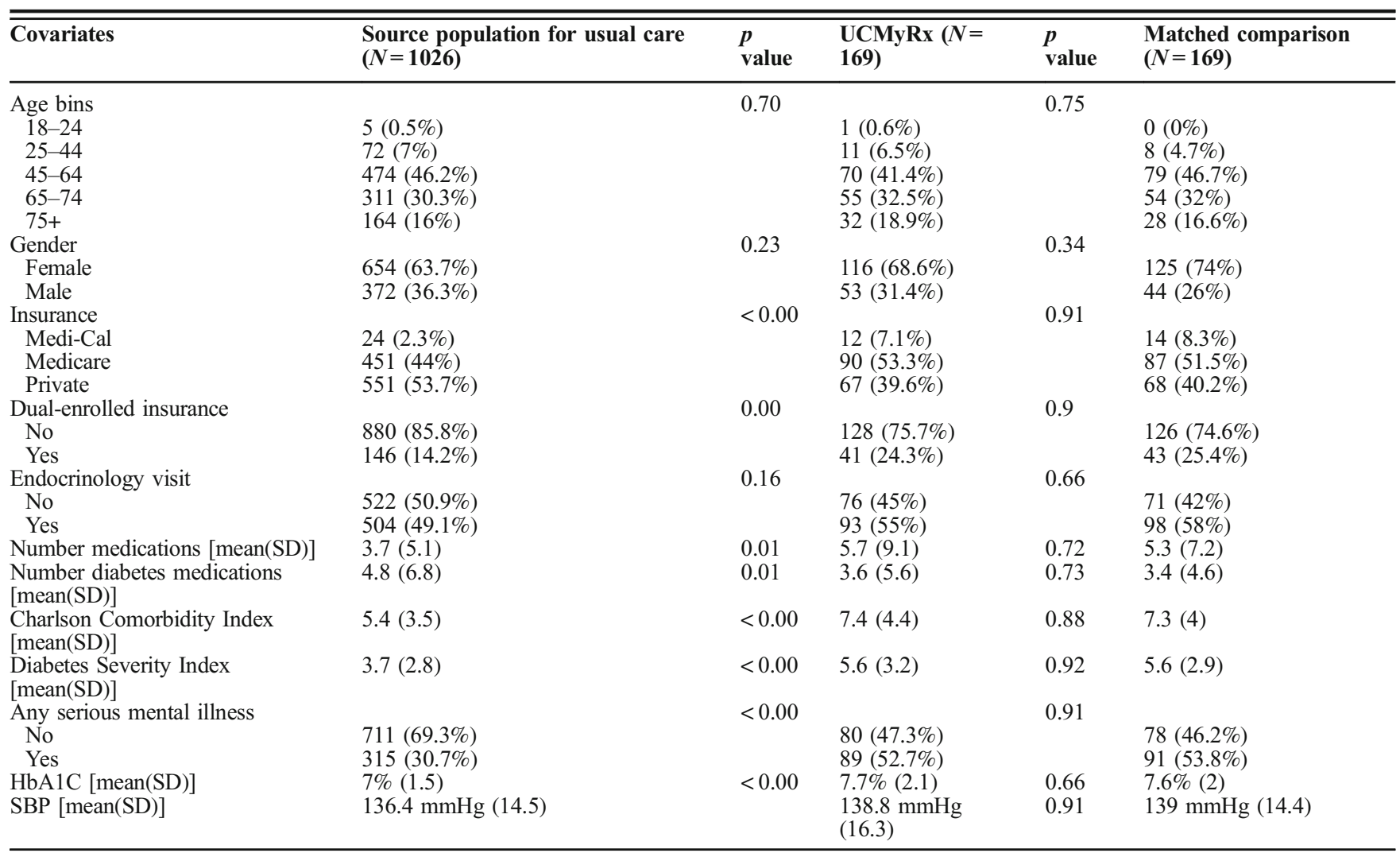

Propensity scores were generated using logistic regression models that included pre-index (HbAlc and SBP levels, age, gender, Charlson Comorbidity Index, Diabetes Severity Index, presence of serious mental illness (bipolar disorder, schizophrenia, major depression), having seen an endocrinologist (yes/no), number of diabetes medications, total number of medications, and health insurance status (private, Medicare, Medicaid, Medicaid + Medicare)). Each treatment patient was matched to one comparison patient using a nearest neighbor matching approach. Bivariates were generated using the t test and chi-squared test for continuous and categorical/dichotomous variables, respectively

to-face contacts and total contacts (face-to-face visits, telephone calls, and e-mails) above the median to those with the median or below, by incorporating an interaction between time and an indicator coded as " 1 " if the number of contacts was above the median and coded " 0 " otherwise, in a model that was limited to UCMyRx patients.

\section{RESULTS}

\section{Patient Characteristics}

Our sample sizes for the $\mathrm{HbAlc}$ and the SBP outcomes were 169 and 210, respectively. Descriptive statistics for each of our unmatched and matched analytic samples are shown in Table 2 (HbA1c sample) and Table 3 (SBP sample). The pre-index mean $\mathrm{HbA} 1 \mathrm{c}$ for the sample used for the $\mathrm{HbA} 1 \mathrm{c}$ analysis was $7.7 \%$ and the SBP for the sample used for the SBP analysis was $138.5 \mathrm{mmHg}$.

\section{UCMyRx Characteristics}

The mean and standard deviation for face-to-face visits for the HbA1c and SBP groups were 3.8 (5.5) and 3.6 (5.1), respectively. The median and interquartile range for face-to-face visits for both the HbAlc and SBP groups was $2(1-4)$. The mean and standard deviation for total contacts (face-to-face visits, telephone, and e-mail) for the HbA1c and SBP groups were 7.1 (11.2) and $6.6(10.4)$, respectively. The median and interquartile range for total contacts for both the $\mathrm{HbA} 1 \mathrm{c}$ and SBP groups was $3(2-8)$.

\section{Post UCMyRx Visit Change in HbAlc and SBP}

The results of our adjusted analyses are shown in Table 4 . Patients exposed to the UCMyRx intervention experienced a significant $-0.40 \%$ ( $p$ value $=0.01)$ decline in $\mathrm{HbA1c}$, relative to usual care patients. The median $\mathrm{HbA} 1 \mathrm{c}$ change among UCMyRx patients was $-0.20 \%$ and the interquartile range was -0.20 to $-0.90 \%$. There was also an insignificant negative trend in SBP among UCMyRx-exposed patients $(-.051 \mathrm{mmHg}(p$ value $=0.74))$.

\section{Sensitivity Analyses}

The analysis limited to individuals with $\mathrm{HbA} 1 \mathrm{c} \geq 9 \%$ shows a UCMyRx effect slightly larger than that observed in the initial analysis $(-0.45 \%, p$ value $=0.01$ vs. $-0.40 \%, p$ value $=0.01$ ) ; however, this difference in magnitude is not statistically significant $(-0.43, p$ 
Table 3 Descriptive Statistics by Treatment Status for the SBP Sample (Unmatched and Matched)

\begin{tabular}{|c|c|c|c|c|c|}
\hline Covariates & $\begin{array}{l}\text { Source population for usual care } \\
(N=1298)\end{array}$ & $\begin{array}{l}p \\
\text { value }\end{array}$ & $\begin{array}{l}\text { UCMyRx }(N= \\
210)\end{array}$ & $\begin{array}{l}p \\
\text { value }\end{array}$ & $\begin{array}{l}\text { Matched comparison } \\
(N=210)\end{array}$ \\
\hline Age bins & & 0.44 & & 0.90 & \\
\hline $18-24$ & $9(0.7 \%)$ & & $2(1 \%)$ & & $1(0.5 \%)$ \\
\hline $25-44$ & $102(7.9 \%)$ & & $12(5.7 \%)$ & & $13(6.2 \%)$ \\
\hline $45-64$ & $598(46.1 \%)$ & & $88(41.9 \%)$ & & $93(44.3 \%)$ \\
\hline $65-74$ & $368(28.4 \%)$ & & $67(31.9 \%)$ & & $59(28.1 \%)$ \\
\hline $75+$ & $221(17 \%)$ & & $41(19.5 \%)$ & & $44(21 \%)$ \\
\hline Gender & & 0.10 & & 1.00 & \\
\hline Female & $832(64.1 \%)$ & & $147(70 \%)$ & & $146(69.5 \%)$ \\
\hline Male & $466(35.9 \%)$ & & $63(30 \%)$ & & $64(30.5 \%)$ \\
\hline Insurance & & $<0.00$ & & 0.84 & \\
\hline Medi-Cal & $31(2.4 \%)$ & & $17(8.1 \%)$ & & $15(7.1 \%)$ \\
\hline Medicare & $579(44.6 \%)$ & & $110(52.4 \%)$ & & $116(55.2 \%)$ \\
\hline Private & $688(53 \%)$ & & $83(39.5 \%)$ & & $79(37.6 \%)$ \\
\hline Dual-enrolled insurance & & 0.00 & & 0.91 & \\
\hline No & $1109(85.4 \%)$ & & $162(77.1 \%)$ & & $160(76.2 \%)$ \\
\hline Yes & $189(14.6 \%)$ & & $48(22.9 \%)$ & & $50(23.8 \%)$ \\
\hline Endocrinology visit & & 0.26 & & 0.92 & \\
\hline No & $693(53.4 \%)$ & & $103(49 \%)$ & & $101(48.1 \%)$ \\
\hline Yes & $605(46.6 \%)$ & & $107(51 \%)$ & & $109(51.9 \%)$ \\
\hline Number medications [mean(SD)] & $3.9(5.7)$ & 0.00 & $6.4(10.4)$ & 0.92 & $6.3(8.9)$ \\
\hline $\begin{array}{l}\text { Number diabetes medications } \\
{[\text { mean(SD)] }}\end{array}$ & $4.4(6.5)$ & 0.04 & $3.4(6)$ & 0.92 & $3.4(5.3)$ \\
\hline $\begin{array}{l}\text { Charlson Comorbidity Index } \\
\text { [mean(SD)] }\end{array}$ & $5.4(3.6)$ & $<0.00$ & $7.3(4.4)$ & 0.99 & $7.3(4.2)$ \\
\hline $\begin{array}{l}\text { Diabetes Severity Index } \\
\text { [mean(SD)] }\end{array}$ & $3.7(2.8)$ & $<0.00$ & $5.4(3.2)$ & 0.94 & $5.4(3.2)$ \\
\hline Any serious mental illness & & $<0.00$ & & 0.63 & \\
\hline No & $891(68.6 \%)$ & & $101(48.1 \%)$ & & $95(45.2 \%)$ \\
\hline Yes & $407(31.4 \%)$ & & $109(51.9 \%)$ & & $115(54.8 \%)$ \\
\hline $\mathrm{HbA} 1 \mathrm{C}[\mathrm{mean}(\mathrm{SD})]$ & $7 \%(1.6)$ & $<0.00$ & $7.5 \%(2.1)$ & 0.98 & $7.5 \%(2.1)$ \\
\hline SBP $[$ mean $(\mathrm{SD})]$ & $136.7 \mathrm{mmHg}(14.6)$ & 0.16 & $\begin{array}{l}138.5 \mathrm{mmHg} \\
(16.3)\end{array}$ & 0.44 & $137.3 \mathrm{mmHg}(16.2)$ \\
\hline
\end{tabular}

Propensity scores were generated using logistic regression models that included pre-index (HbAlc and SBP levels, age, gender, Charlson Comorbidity index, Diabetes Severity Index, presence of serious mental illness (bipolar disorder, schizophrenia, major depression), having seen an endocrinologist (yes/no), number of diabetes medications, total number of medications, and health insurance status (private, Medicare, Medicaid, Medicaid + Medicare)). Each treatment patient was matched to one comparison patient using a nearest neighbor matching approach. Bivariates were generated using the t test and chi-squared test for continuous and categorical/dichotomous variables, respectively

value $=0.36$ ). There is an insignificant negative trend among the population with $\mathrm{SBP} \geq 150 \mathrm{mmHg}$, at least once during the pre-index period $(-0.50 \mathrm{mmHg}, p$ value $=0.76$ ). In CCI-stratified analyses, we found that the intervention effect on $\mathrm{HbA} 1 \mathrm{c}$ is stronger $(-0.79 \%, p$ value $=0.00$ vs. $-0.40 \%, p$ value $=0.01)$ among the tercile with the lowest comorbidity score $(\mathrm{CC} 1 \leq 5)$. UCMyRx effects are not statistically significant in the other terciles $(5<\mathrm{CC} 1 \leq 8=-0.30 \%, p$ value $=0.22$; CCI $>8=-0.05 \%, p$ value $=0.84)$. We do not find statistically significant effects of the UCMyRx intervention

Table 4 Results of the Analysis of the Impact of the UCMyRx Intervention on Cardiovascular Risk Factors Among Blacks with Type 2 Diabetes

\begin{tabular}{llllll}
\hline \hline Covariates & HbA1c & & \multicolumn{2}{l}{ SBP } \\
\cline { 2 - 3 } & $\boldsymbol{\beta}$ & $\boldsymbol{p}$ value & & $\boldsymbol{\beta}$ & $\boldsymbol{p}$ value \\
\hline Time & -0.04 & 0.68 & & -0.54 & 0.61 \\
UCMyRx & 0.10 & 0.63 & & 1.22 & 0.44 \\
Time $\times$ UCMyRx & -0.40 & 0.01 & & -0.51 & 0.74 \\
\hline
\end{tabular}

Beta coefficients are generated using difference-in-differences (DID) analyses with linear mixed effects models that included fixed effects for time (post vs. pre), group (UCMyRx vs. comparison), and the interaction between time and group among our matched samples. SBP systolic blood pressure; $1, N=169 ; 2, N=210$ on SBP in any CCI tercile. We found an insignificant trend towards stronger UCMyRx effects among the HbA1c subgroups with more face-to-face visits ($0.372, p$ value $=0.065)$ and total contacts $(-0.369, p$ value $=0.066)$, respectively.

\section{DISCUSSION}

We conducted the first effectiveness study of a primary careembedded clinical pharmacist-led intervention in a large healthcare system, among black patients with type 2 diabetes and found a statistically significant $0.4 \%$ reduction in $\mathrm{HbAlc}$ among the UCMyRx population and no impact on SBP, relative to usual care. We find an even stronger $\mathrm{HbA} 1 \mathrm{c}$ effect among individuals with low levels of comorbidity and borderline stronger effects among individuals with more UCMyRx contacts.

A HbAlc reduction of $0.4 \%$ is consistent with what some studies have found for continuous glucose monitoring and insulin initiation. ${ }^{23,}{ }^{24}$ Economic models have predicted that a $0.4 \%$ decrease in HbAlc would significantly reduce microvascular and macrovascular complications among diabetics, over 25 years, taking into account age, gender, risk factors, and pre-existing complications. ${ }^{25,} 26$ Given that blacks suffer more 
diabetes-related morbidity and mortality than nearly all other racial/ethnic subgroups, these findings are particularly important.

The effect on HbAlc that we find is roughly $50 \%$ of what has been observed in efficacy studies. ${ }^{14}$ Several factors may account for that. One factor may be that the mean $\mathrm{HbAlc}$ in our analytic sample is lower relative to that of other study populations (7.7\% vs.11\%). ${ }^{14}$ We also have an older study population than what has been found in other studies, with a mean age of 63.7, relative to a mean age of 54 and 59 in the Rothman et al. and Jaber et al. studies, respectively. ${ }^{14,} 15$ Consequently, less stringent $\mathrm{HbAlc}$ treatment goals for some older patients may have manifested in a smaller mean $\mathrm{HbAlc}$ change associated with the UCMyRx intervention. ${ }^{27}$ Lastly, relative to other studies, our treatment populations had much less contact with clinical pharmacists. In the Rothman et al. study, the diabetes management team had a median of 45 contacts/care-related activities per patient, relative to 3 in this study for the HbAlc subsample. ${ }^{14}$

These findings must be interpreted in the context of important study limitations. Our DID analysis with propensity score-matched comparison group will only remove the influence of secular time trends from our UCMyRx effectestimates if the secular time trends for the UCMyRx and usual care groups are the same. ${ }^{21}$ Propensity score matching helps to ensure the similarity of secular time trends across groups by matching study participants on observable characteristics; however, this approach does not address non-observable differences such as patient activation. ${ }^{28}$ Another limitation is that this analysis only looks at the short-term effects of the UCMyRx intervention. Lastly, this study was done in a large academic healthcare system; therefore, findings may be different in other types of settings.

This study makes a number of contributions to the literature. Foremost, this study shows that even when delivered at an intensity levels lower than what has been observed in RCTs and among patient populations not meeting stringent selection criteria, a primary careembedded clinical pharmacist-led intervention leads to meaningful improvements in HbAlc levels, among blacks with type 2 diabetes, relative to usual care. Interventions such as UCMyRx may prove more financially feasible for a diverse range of medical practices to adopt, relative to the intervention strategies used in the RCTs. Secondly, given that the effect of UCMyRx on HbAlc was commiserate with what has been observed for interventions such as insulin initiation and prescription oral medications (lowest comorbidity tercile effects) with fewer adverse effects, it will be important for health insurance companies to reimburse appropriately for these interventions. Another benefit of interventions like UCMyRx is the ability to help unburden physicians while improving the quality of diabetes care for patients. Lastly, UCMyRx increases patient self-management opportunities by addressing structural barriers that preclude engagement in care, which are highly prevalent among the black patient population, irrespective of health insurance coverage status. Consequently, interventions such as UCMyRx may help reduce diabetes disparities among blacks.

\section{CONCLUSION}

Using a difference-in-differences study design with a propensity-matched comparison group, we found that a primary care-embedded clinical pharmacist-led intervention in a large healthcare system led to a significant reduction in $\mathrm{HbAlc}$ among black patients with type 2 diabetes, relative to usual care.

Acknowledgments: The authors thank Richard Maranon and Janet Chon for providing additional insight into the UcMyRx program and for providing feedback on the manuscript.

Corresponding Author: Kimberly Danae Cauley Narain, $M D, P h D$, MPH; Department of Medicine, Division of General Internal Medicine and Health Services Research (GIM/HSR), University of California, Los Angeles, 1100 Glendon Ave., Suite 850, Los Angeles, CA 90024, USA (e-mail: KNarain@mednet.ucla.edu).

Funding Information Dr. Carol M. Mangione received support from the University of California at Los Angeles (UCLA), Resource Centers for Minority Aging Research Center for Health Improvement of Minority Elderly under National Institutes of Health (NIH)/NIA under Grant P30AG021684, and the Delivery System Reform Incentive Pool (DSRIP) under a Grant from the Centers for Medicare \& Medicaid Services (CMS). Dr. Mangione holds the Barbara A. Levey and Gerald S. Levey Endowed Chair in Medicine, which partially supported her work. Dr. Carol M. Mangione is a member of the United States Preventive Services Task Force (USPSTF). This research was supported by NIH National Center for Advancing Translational Science (NCATS) UCLA CTSI Grant Number UL1TROO1881.

\section{Compliance with Ethical Standards:}

Conflict of Interest: The authors declare that they do not have a conflict of interest.

Disclaimer: This article does not necessarily represent the views and policies of the USPSTF.

\section{REFERENCES}

1. Association, A. D. Economic Costs of Diabetes in the U.S. in 2017. Diabetes Care. 2018 May;41(5):917-928. doi:https://doi.org/10.2337/ dci18-0007.

2. Canedo, J. R., Miller, S. T., Schlundt, D., Fadden, M. K. \& Sanderson, M. Racial/Ethnic Disparities in Diabetes Quality of Care: the Role of Healthcare Access and Socioeconomic Status. J. Racial Ethn. Health Disparities. 2018 Feb;5(1):7-14.

3. Goode, P. Diabetes Disparities in African Americans: A Cry for Help to Primary Care Providers. J Health Dispar Res Prac. 2017 10(4):61-66.

4. Jensen, G. A. \& Li, Y. Long-run health effects of cost-related nonadherence to prescribed medications among adults in late midlife. J. Pharm. Health Serv. Res. 2012 May 3:85-93.

5. Goyal, A. et al. Racial Differences in the Attainment of Cardiovascular Risk Factor Goals Among Insured Adults with Diabetes Mellitus. J. Am. Coll. Cardiol. 2010 March 55: A142.E1332.

6. Holland, A. T. et al. Racial/ethnic differences in control of cardiovascular risk factors among type 2 diabetes patients in an insured, ambulatory care population. J. Diabetes Complications. 2013 Jan-Feb 27(1): 34-40. 
7. Peek, M. E., Cargill, A. \& Huang, E. S. Diabetes Health Disparities. Med. Care Res. Rev. 2007 Oct;64(5 Suppl):101S-156S.

8. Gerber, B. S., Cho, Y. I., Arozullah, A. M. \& Lee, S.-Y. D. Racial differences in medication adherence: A cross-sectional study of Medicare enrollees. Am. J. Geriatr. Pharmacother. 2010 Apr;8(2):136-145.

9. Trinacty, C. M. et al. Racial differences in long-term adherence to ora antidiabetic drug therapy: a longitudinal cohort study. BMC Health Serv. Res. 2009 Feb;9:24.

10. Zhang, J. X., Lee, J. U. \& Meltzer, D. O. Risk factors for cost-related medication non-adherence among older patients with diabetes. World $J$. Diabetes. 2014 Dec;5(6):945-950.

11. Osborn, C. Y. et al. Health literacy explains racial disparities in diabetes medication adherence. J. Health Commun. 2011;16 Suppl 3:268-278.

12. Kurlander, J. E., Kerr, E. A., Krein, S., Heisler, M. \& Piette, J. D. Costrelated nonadherence to medications among patients with diabetes and chronic pain: factors beyond finances. Diabetes Care. 2009 Dec;32(12):2143-2148.

13. Adams, A. S., Banerjee, $\mathbf{S}$. \& Ku, C. J. Medication adherence and racial differences in diabetes in the USA: an update. Diabetes Manag. 2015;5:79-87.

14. Rothman, R. L. et al. A randomized trial of a primary care-based disease management program to improve cardiovascular risk factors and glycated hemoglobin levels in patients with diabetes. Am. J. Med. 2005 Mar;118(3):276-284.

15. Jaber, L. A., Halapy, H., Fernet, M., Tummalapalli, S. \& Diwakaran, H. Evaluation of a Pharmaceutical Care Model on Diabetes Management. Ann. Pharmacother. 1996 Mar;30(3):238-243.

16. Singal, A. G., Higgins, P. D. R. \& Waljee, A. K. A Primer on Effectiveness and Efficacy Trials. Clin. Transl. Gastroenterol. 2014 Jan;5:e45.

17. Ackermann, R. T. et al. Evaluating Diabetes Health Policies Using Natural Experiments: The Natural Experiments for Translation in Diabetes Study. Am. J. Prev. Med. 2015 Jun;48(6):747-754.

18. Joish, V. N., Malone, D. C., Wendel, C., Draugalis, J. R. \& Mohler, M. J. Development and Validation of a Diabetes Mellitus Severity Index: A Risk Adjustment Tool for Predicting Health Care Resource Use and Costs. Pharmacother. J. Hum. Pharmacol. Drug Ther. 2005 May;25(5):676-684.

19. Ryan, J. G., Fedders, M., Jennings, T., Vittoria, I. \& Yanes, M. Clinica outcomes and incremental costs from a medication adherence pilot intervention targeting low-income patients with diabetes at risk of costrelated medication nonadherence. Clin. Ther. 2014 Dec;36(12):19912002

20. Stuart, E. A. Matching methods for causal inference: A review and a look forward. Stat. Sci. Rev. J. Inst. Math. Stat. 2010 Feb;25(1):1-21.

21. Zhou, H., Taber, C., Arcona, S. \& Li, Y. Difference-in-Differences Method in Comparative Effectiveness Research: Utility with Unbalanced Groups. Appl. Health Econ. Health Policy. 2016 Aug;14(4):419-429.

22. Winter, B. Linear models and linear mixed effects models in R with linguistic applications. 2013: ArXiv13085499 Cs.

23. Bailey, T. S., Zisser, H. C. \& Garg, S. K. Reduction in hemoglobin A1C with real-time continuous glucose monitoring: results from a 12-week observational study. Diabetes Technol. Ther. 2007 Jun;9(3):203-210.

24. Bhattacharya, R., Zhou, S., Wei, W., Ajmera, M. \& Sambamoorthi, U. A Real-World Study of the Effect of Timing of Insulin Initiation on Outcomes in Older Medicare Beneficiaries with Type 2 Diabetes Mellitus. J. Am. Geriatr. Soc. 2015 May;63(5):893-901.

25. Baxter, M. et al. Estimating the impact of better management of glycaemic control in adults with Type 1 and Type 2 diabetes on the number of clinical complications and the associated financial benefit. Diabet. Med. 2016 Nov;33(11):1575-1581.

26. Palmer, A. J. et al. The CORE Diabetes Model: Projecting long-term clinical outcomes, costs and cost-effectiveness of interventions in diabetes mellitus (types 1 and 2) to support clinical and reimbursement decisionmaking. Curr. Med. Res. Opin. 2004 Aug;20 Suppl 1:S5-26.

27. Kalyani, R. R., Golden, S. H. \& Cefalu, w. T. Diabetes and Aging: Unique Considerations and Goals of Care. Diabetes Care. 2017 Apr;40(4):440-443.

28. Stuart, E. A. et al. Using propensity scores in difference-in-differences models to estimate the effects of a policy change. Health Serv. Outcomes Res. Methodol. 2014 Dec;14(4):166-182.

Publisher's Note Springer Nature remains neutral with regard to jurisdictional claims in published maps and institutional affiliations. 